\title{
Features of Shaping Blanks for the Assembly of Non-Removable Plastic Deformation Joints
}

\author{
${ }^{1}$ Ainur Minnegayanovich Valiev, ${ }^{2}$ Dmitry Leonidovich Pankratov, ${ }^{3}$ Shibakov Vladimir Georgievich \\ 1,2,3 Department of Mechanical Engineering, Naberezhnye Chelny Institute, KFU \\ AjMValiev@kpfu.ru \\ dlpankratov@kpfu.ru \\ VlGShibakov@kpfu.ru
}

Received: 21st August 2020, Accepted: 14th September 2020, Published: 31st October 2020

\begin{abstract}
The work is aimed at the manufacturing process improvement of one-piece products by the deformation of plastic via the means of preliminary shaping of blanks before assembly. The shaped form of a workpiece provides the process of forming the workpiece according to the open piercing scheme with the formation of an annular gap with a minimum barrel-shaped side surface without sinking at the stage of rod penetration, and the localization of deformation only in the embedded part of the rod at the stage of the rod upsetting when the walls limit the form change of the side surface. Using simulation modelling in the QForm software package, they performed the studies of cylindrical image shape change with open piercing for various ratios of the workpiece and the rod geometric dimensions, as well as the studies of the rod end shape change. The main regularities of cylindrical specimen shape change were obtained as the result of the piercing. The fundamental feature of the blank shape change with open piercing is the likelihood of a closed annular gap formed between the lateral surface of the rod and the resulting cavity in the blank. The piercing continually goes with the formation of sinking at the end of the workpiece from the side of the rod penetration. On the basis of the research carried out, mathematical models of workpiece shaping is created, which allow to take into account the unevenness of deformation during assembly and guarantee the adequate quality of the obtained a one-piece product with the deviation of geometric parameters within the range of precise hot forging.
\end{abstract}

\section{Keywords}

One-Piece Products; Plastic Deformation; Shaping; Shaping Of Blanks; Uneven Deformation

\section{Introduction}

The usage of one-piece products in mechanical engineering has been dictated by a number of advantages that they have in comparison with the products made of one material. The main advantage is the significant savings in expensive steels, alloys and metals while maintaining the level of functional properties [7;4].

So, for example, the reduction of tool costs by saving expensive alloy steels is an urgent task for tool production. In some cases, this problem can be solved by composite tool use, which is a one-piece product, in which the most loaded working part is made of tool steel, and other structural elements are made of cheap carbon steel.

Today, there are many different ways to make one-piece products. In $[6 ; 9 ; 8]$, the classification of the most common methods of joining metals is proposed to use the presence or absence of plastic deformation. Thus, all methods are divided into two broad groups: the methods with the use of plastic deformation (at least one of the components) and the methods without plastic deformation. The first group includes the methods based on pressure welding, namely: pressing (extrusion), rolling, press welding, resistance welding, diffusion welding, explosion welding, friction welding, cold welding, etc. The second group includes the methods based on fusion welding, namely: casting, cladding, brazing, fusion welding, sputtering, chemical and electrolytic coating methods, and vapour deposition. Fusion welding is based on the fact that the edges of the metals to be joined are melted, the gap between them is filled with molten metal (including filler metal), and a joint is formed. A significant disadvantage of fusion welding is the possibility of various defects development in the metal joining zone, the appearance of brittle phases and intermetallic compounds due to metal melting.

The measures to acquire the parts' joints through the deformation of plastic are on the basis of a permanent joint obtaining at the temperature under the melt temperature of the metals in the processes of melting. Simultaneously, there are almost no zones of structural and chemical heterogeneity in the joint area inherent in the methods of joining parts by fusion welding [1].

Figure. 1 reveals the proposed method's diagram to assemble the axisymmetric one-piece metal product with a barrelshaped form of joined surfaces, consisting of four successive stages. The shaped blank 2 and the rod 1 embedded in it act as the connected elements of a one-piece product [10]. 


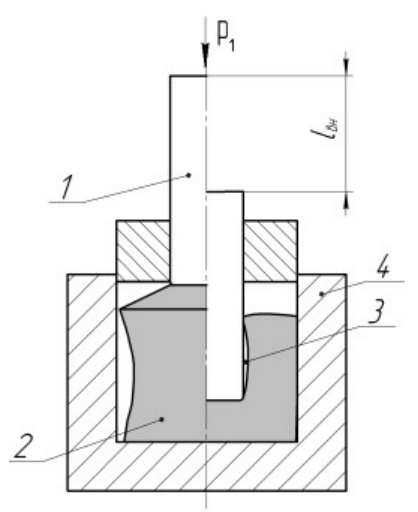

a)

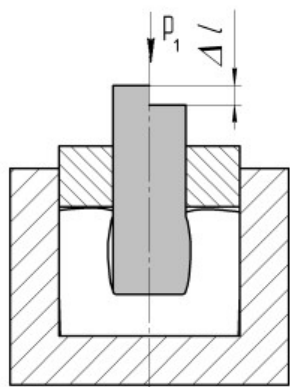

b)
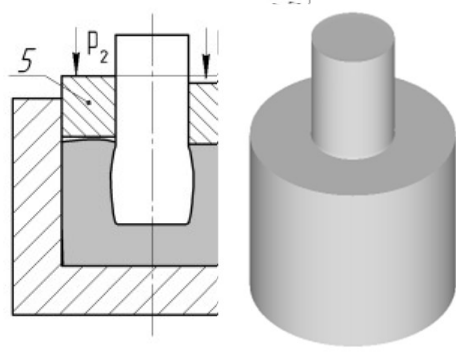

d)

Figure 1: Diagram of the Method for One-piece Product Assembling Note: The deformable object at the corresponding stage is marked in gray on the figure

At the initial step, the rod 1 is introduced into the shaped workpiece 2 heated to forging temperatures, within the matrix 4 to the depth $1_{\text {wn }}$ (Fig. 1, a). At the second stage ("Holding") the joint is held during $\tau_{\text {cr }}$ to warm up the embedded part of the rod to reduce the yield stress of its material. Subsequently, at stage three ("The rod upsetting"), the embedded part of the rod is upset by the value $\Delta \mathrm{l}$, because of which the third annular gap is filled with the rod material (Figure 1, b). Next, at stage four ("Final assembly"), the last assembly is carried out with the ring tool 5 at $\Delta \mathrm{H}_{\mathrm{d}}$. (Figure 1, c). Figure 1 (d) demonstrates the 3D assembled elements model.

The shaped form of the workpiece provides the process of forming the workpiece according to the open piercing scheme with the formation of an annular gap with a minimum barrel-shaped side surface without sinking at the stage of rod penetration (Fig. 1, a), and localization of deformation only in the embedded part of the rod at the stage of the rod upsetting, when the deformation of the lateral surface is limited by the matrix walls (Fig. 1, b).

Hence, the accomplishment of the particular indicators of the assembly quality for one-piece products, including the accuracy of the geometric product dimensions and the strength of the permanent connection, relies on the precise calculation of the shaped workpiece geometric factors.

\section{Methods}

The main methods for studying the process were regression analysis and simulation modelling of plastic flow of metal in the Deform-2D software package.

The chief geometrical parameters of the open piercing process of a cylindrical workpiece with the height $\mathrm{H}_{0}$ and the diameter $\mathrm{D}_{0}$ (contour 1) with a cylindrical punch (rod) with the diameter $d_{p}$ with the taper angle $\alpha$ (Fig. 2) were established experimentally. After piercing, the workpiece is upset, and its height becomes equal to $\mathrm{H}_{\mathrm{k}}$. The piercing procedure is constantly come by the contraction puncheon formation on the side of the punch penetration at blank's end, which is able to quantitatively classified by the angle $\varphi$. 


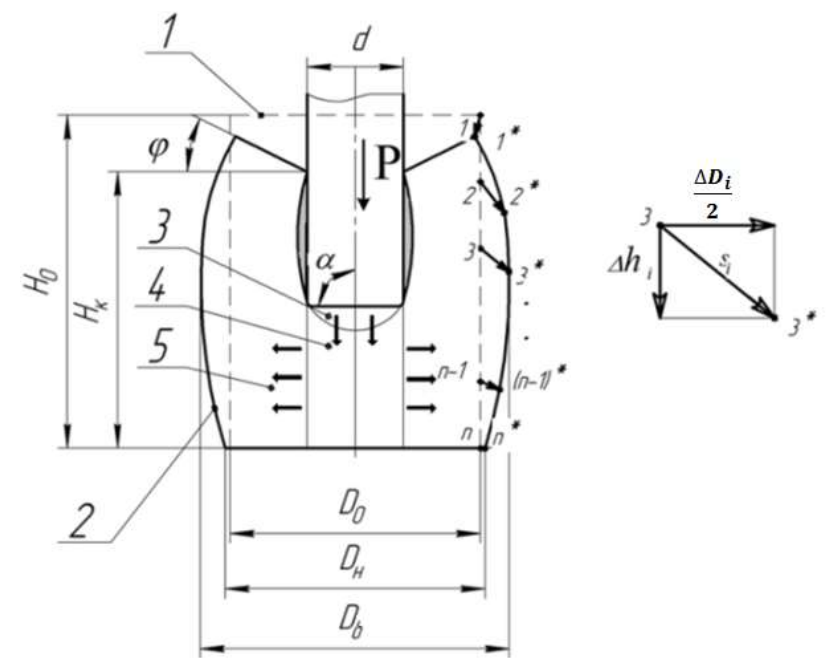

Figure 2: Analysis of a Cylindrical Blank Shape Change with Open Piercing

The workpiece becomes barrel-shaped with the barrel diameter $D_{b}$ (contour 2). To specify the workpiece metal displacement with open piercing accurately in order to figure out the last shape change of the workpiece, the $\mathrm{D}_{b}$ and $\mathrm{H}_{\mathrm{k}}$ values are not enough. In this regard, let's denote the points i equidistant from one another and introduce the vector of i-point displacement $\vec{s}_{i}\left(\frac{\Delta D_{i}}{2}, \Delta H_{i}\right)$ from their initial position $1,2, \ldots \mathrm{n}$ to the finite one $1^{*}, 2^{*}, \ldots \mathrm{n} *$ on the lateral surface of the workpiece. The components $\frac{\Delta D_{i}}{2}$ and $\Delta H_{i}$-are the displacement values of the i-th point in the radial and axial directions, respectively. The $\mathrm{D}_{\mathrm{i}}$ value is the diameter of the workpiece at the $\mathrm{i}$-th point, and the $\mathrm{H}_{\mathrm{i}}$ value is the distance of the $\mathrm{i}$-th point from the lower base of the workpiece.

A characteristic feature of the workpiece shape change with open piercing is the possibility of a closed annular gap formation. Nowadays, this process has not been studied sufficiently.

The formation of a closed annular gap is an undesirable process for traditional technological processes of open piercing, since it leads to the cylindrical surface wear of the punch, creates difficulties of its extraction, while tensile stresses arise in it, which increases the labour intensity of the resulting cavity machining, etc.

To quantify the annular gap, it is proposed to use the following relative value:

$\theta=\frac{V_{\theta}}{V_{\text {in }}} 100 \%$

where $V_{\theta}$ is the volume of the annular gap, $\mathrm{mm}^{3}$ (figure);

$V_{\text {in }}=\frac{\pi \cdot d}{4} \cdot l_{\text {in }}, \mathrm{mm}^{3}-$ the volume of the part of the cylindrical punch part inserted into the workpiece to the depth $l_{\text {in }}$.

On the other hand, the formation of a closed annular gap is a prerequisite for the implementation of the proposed method for composite product manufacture by plastic deformation. In this regard, it is necessary to determine the conditions of an annular gap development with an open piercing, to establish the corresponding dependences of an annular gap formation process.

In order to determine the conditions under which the formation of an annular gap with open piercing occurs, the process was studied using simulation in the Deform-2D software package, which makes it possible to simulate the process with contact friction conditions not only encountered in real deformation conditions $(\mu=0.15 \div 0.45)$, but for ideal cases: $\mu=0$ (absolute absence of friction forces on the contact surface) and $\mu=0.57$ (absolute dry friction), where $\mu$ is the Siebel friction coefficient. The piercing was carried out with the punches the diameter of which makes $\mathrm{d}=0.5 \mathrm{D}$ to the depth of $80 \%$ of the initial sample height with the taper angles $\alpha=45^{\circ}, 60^{\circ}, 75^{\circ}$ and $90^{\circ}$.

After the study, the task of mathematical model development for the dependences of the workpiece final shape change dimensions $\Delta \mathrm{D}_{\mathrm{i}}, \Delta \mathrm{H}_{\mathrm{i}}, \Delta \mathrm{D}_{\mathrm{b}}, \Delta \mathrm{H}_{\mathrm{k}}, \varphi, \theta$ on the relative diameter of the rod (punch) $\mathrm{d} / \mathrm{D}_{0}$, the relative height of the workpiece $\mathrm{H}_{0} / \mathrm{D}_{0}$, and the angle at the base of the $\operatorname{rod} \alpha$.

In order to develop universal mathematical models of the workpiece shape change parameters $\Delta \mathrm{D}_{\mathrm{i}}, \Delta \mathrm{H}_{\mathrm{i}}, \mathrm{D}_{\mathrm{b}}$ and $\mathrm{H}_{\mathrm{k}}$ during the rod introduction, it is proposed to use their relative values in order to get away from the absolute values:

$\Delta D_{i}^{*}=\frac{D_{i}-D_{0}}{D_{0}} \cdot 100 \%$ 
$\Delta H_{i}^{*}=\frac{H_{i}-H_{i_{0}}}{H_{i_{0}}} \cdot 100 \%$

$\Delta D_{b}^{*}=\frac{D_{6}-D_{0}}{D_{0}} \cdot 100 \%$

$\Delta H_{k}^{*}=\frac{H_{k}-H_{0}}{H_{0}} \cdot 100 \%$

Thus, it is necessary to develop the following set of mathematical models:

$\Delta D_{i}^{*}=f_{1}\left(d / D_{0} ; H_{0} / D_{0} ; \alpha\right)$

$\Delta H_{i}^{*}=f_{2}\left(d / D_{0} ; H_{0} / D_{0} ; \alpha\right)$

$\Delta D_{b}^{*}=f_{3}\left(d / D_{0} ; H_{0} / D_{0} ; \alpha\right)$

$\Delta H_{k}^{*}=f_{4}\left(d_{\Pi} / D_{0} ; H_{0} / D_{0} ; \alpha\right)$

$\varphi=f_{5}\left(d / D_{0} ; H_{0} / D_{0} ; \alpha\right)$

$\theta=f_{6}\left(d / D_{0} ; H_{0} / D_{0} ; \alpha\right)$

Using simulation modelling in the QForm software package, they carried out the studies of cylindrical image shape change with open piercing for various ratios of the workpiece and the rod geometric dimensions, as well as for the rod end shape. The accepted values of the variable factors: relative diameter of the rod $\mathrm{d} / \mathrm{D}_{0}=0.3 \div 0.7$; relative height of the workpiece $\mathrm{H}_{0} / \mathrm{D}_{0}=0.5 \div 1.5$. (at large values of $\mathrm{H}_{0} / \mathrm{D}_{0}$ it is difficult to ensure the rod stability); the angle at the base of the punch $\alpha=45^{\circ} \div 90^{\circ}$. The punch penetration depth is $0.8 \mathrm{H}_{0}$ (a large piercing depth leads to the formation of a removable bridge and is mainly used for a through-hole piercing in a workpiece).

\section{Results and Discussion}

The study found that with open piercing and a punch with $\alpha=90^{\circ}$, that is, with a flat end, the final shape change of the lateral surface is almost independent of contact friction conditions and is always accompanied by an annular gap development. This is due to the fact that there is a massive ring (see Fig. 2, zone 5) around the deformable area of the metal (see Fig. 2, zone 4), which has a greater restraining reactive effect than the contact friction forces, and, therefore, other things being equal, frictional conditions have almost no effect on the final shape change during piercing. For the punches with end taper angles $\alpha=45^{\circ}, 60^{\circ}$ and $75^{\circ}$, the experimental results indicate the influence of contact friction conditions on whether an open piercing will be accompanied by the formation of a closed annular gap or not.

They solved the problem of determining the range of $\mu$ values for the punches with $\alpha \neq 90^{\circ}$, at which the guaranteed formation of a closed annular gap occurs. After experimental studies, the values of the friction coefficient minimum $\mu_{\min }$ have been established, at which open piercing with the punches and diameters od $\mathrm{d} / \mathrm{D}_{0}=0.3 \div 0.7$ is accompanied by the formation of a closed annular gap (Figure 3).

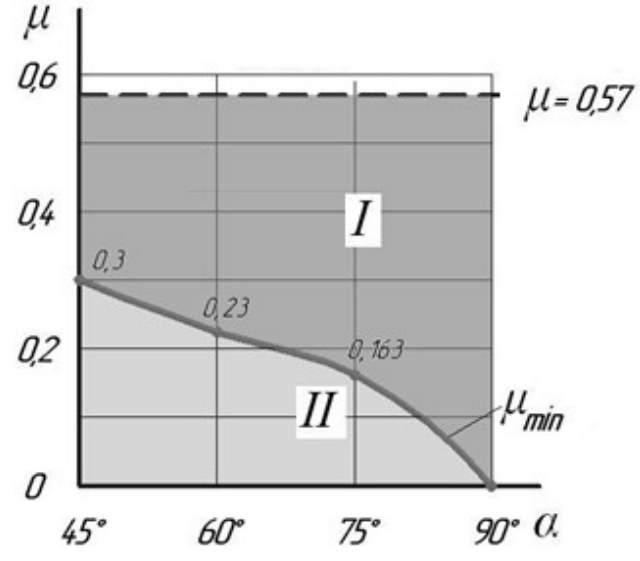

Figure 3: Determination of $\mu_{\min }$ 
The region I correspond to the pair of values at which an open piercing is accompanied by the formation of a closed annular gap. It is characteristic for this region that, other things being equal, the friction forces almost do not affect the final shape change during piercing, i.e. the contours of the lateral sample surface differ insignificantly after deformation.

The region II corresponds to the pair of values at which the open piercing is accompanied either by a slight formation of an annular gap, or the gap is formed open, which significantly reduces the wear of the piercing tool. The values of this area correspond to the existing recommendations for the development of product manufacture technologies by plastic deformation using the operation of the open piercing.

Thus, the contact friction conditions must correspond to the values from the region I for the industrial implementation of the proposed method of composite product manufacture by plastic deformation. Besides, it should be taken into account that the process of the rod element introduction must occur without the use of lubricant in order to ensure the cleanliness of the surfaces to be joined when they assemble the permanent joint.

Using the statistical methods for experimental data processing, considered in detail by [2;3;5], mathematical models were obtained:

a) The relative value of the annular gap $\theta$ volume in the form of a polynomial of the third degree:

$$
\begin{aligned}
& \theta=21\left(H_{0} / D_{0}\right)\left(d / D_{0}\right)^{2}-179,444\left(d / D_{0}\right)^{3}+210,964\left(d / D_{0}\right)^{2}-196,68\left(d / D_{0}\right)++182,3\left(H_{0} / D_{0}\right)\left(d / D_{0}\right)- \\
& 70,96\left(H_{0} / D_{0}\right)^{2}\left(d / D_{0}\right)-113,707+344,296\left(H_{0} / D_{0}\right)--286,065\left(H_{0} / D_{0}\right)^{2}+77,937\left(H_{0} / D_{0}\right)^{3} .
\end{aligned}
$$

b) The relative value of the i-point displacement in the radial direction $\Delta \mathrm{D}_{\mathrm{i}}$ in the form of the third degree polynomial of the following form:

$$
\begin{aligned}
& \Delta D_{i}^{*}=A_{1}\left(H_{0} / D_{0}\right)\left(d / D_{0}\right)^{2}+A_{2}\left(d / D_{0}\right)^{3}+A_{3}\left(d / D_{0}\right)^{2}+A_{4}\left(d / D_{0}\right)+ \\
& A_{5}\left(H_{0} / D_{0}\right)\left(d / D_{0}\right)+A_{6}\left(H_{0} / D_{0}\right)^{2}\left(d / D_{0}\right)+A_{7}+A_{8}\left(H_{0} / D_{0}\right)+A_{9}\left(H_{0} / D_{0}\right)^{2}+A_{10}\left(H_{0} / D_{0}\right)^{3}
\end{aligned}
$$

where $A_{1}, \ldots A_{10}$ are the coefficients, the values of which are summarized in Table 1 for each i-point.

Table 1: Coefficients

\begin{tabular}{|c|c|c|c|c|c|c|c|c|c|c|}
\hline$\Delta D_{i}$ & $A_{1}$ & $A_{2}$ & $A_{3}$ & $A_{4}$ & $A_{5}$ & $A_{6}$ & $A_{7}$ & $A_{8}$ & $A_{9}$ & $A_{10}$ \\
\hline$i=1$ & $-36,86$ & 98,06 & $-56,56$ & 74,89 & $-2,74$ & $-5,76$ & 254,11 & $-655,10$ & 534,06 & $-142,13$ \\
\hline$i=2$ & 33,43 & $-122,22$ & 165,71 & $-43,35$ & $-4,87$ & $-8,16$ & $-7,76$ & 35,34 & $-26,20$ & 7,39 \\
\hline$i=3$ & 30,29 & $-326,94$ & 487,42 & $-204,00$ & 32,43 & $-13,28$ & $-123,93$ & 371,84 & $-304,11$ & 81,82 \\
\hline$i=4$ & 38,29 & $-330,00$ & 501,26 & $-210,75$ & 40,35 & $-16,64$ & $-140,14$ & 413,37 & $-339,59$ & 91,57 \\
\hline$i=5$ & 46,43 & $-271,94$ & 414,29 & $-167,58$ & 33,99 & $-17,04$ & $-126,77$ & 365,88 & $-300,64$ & 81,21 \\
\hline$i=6$ & 24,00 & $-165,83$ & 277,51 & $-116,50$ & 48,12 & $-15,52$ & $-129,65$ & 354,56 & $-294,00$ & 79,36 \\
\hline$i=7$ & $-6,29$ & $-73,89$ & 158,62 & $-79,94$ & 64,93 & $-12,16$ & $-145,78$ & 381,28 & $-318,38$ & 85,62 \\
\hline$i=8$ & $-32,57$ & 11,67 & 41,26 & $-43,01$ & 70,21 & $-6,88$ & $-143,26$ & 364,09 & $-305,50$ & 81,83 \\
\hline$i=9$ & $-36,14$ & 114,44 & $-129,49$ & 32,32 & 46,12 & $-0,72$ & $-93,18$ & 219,14 & $-184,55$ & 49,17 \\
\hline$i=10$ & $-28,71$ & 221,94 & $-324,79$ & 132,74 & 1,05 & 6,80 & 0,11 & $-40,01$ & 32,48 & $-9,23$ \\
\hline
\end{tabular}

c) The relative value of the i-point displacement in the axial direction $\Delta \mathrm{H}_{\mathrm{i}}{ }^{*}$ as the polynomial of the third degree of the following form:

$\Delta H_{i}^{*}=A_{1}\left(H_{0} / D_{0}\right)\left(d / D_{0}\right)^{2}+A_{2}\left(d / D_{0}\right)^{3}+A_{3}\left(d / D_{0}\right)^{2}+A_{4}\left(d / D_{0}\right)+$

$A_{5}\left(H_{0} / D_{0}\right)\left(d / D_{0}\right)+A_{6}\left(H_{0} / D_{0}\right)^{2}\left(d / D_{0}\right)+A_{7}+A_{8}\left(H_{0} / D_{0}\right)+A_{9}\left(H_{0} / D_{0}\right)^{2}+A_{10}\left(H_{0} / D_{0}\right)^{3}$

where $A_{1}, \ldots A_{10}$ - the coefficients, the values of which are summarized in Table 2 for each i-point.

Table 2: Coefficients

\begin{tabular}{|c|c|c|c|c|c|c|c|c|c|c|}
\hline$\Delta H_{i}$ & $A_{1}$ & $A_{2}$ & $A_{3}$ & $A_{4}$ & $A_{5}$ & $A_{6}$ & $A_{7}$ & $A_{8}$ & $A_{9}$ & $A_{10}$ \\
\hline$i=1$ & 14,86 & 12,50 & $-41,42$ & 31,92 & $-18,66$ & 2,40 & 21,35 & $-61,03$ & 51,58 & $-14,01$ \\
\hline$i=2$ & $-98,00$ & 92,50 & $-13,44$ & $-20,29$ & 60,96 & 1,12 & 106,83 & $-258,91$ & 200,29 & $-53,48$ \\
\hline$i=3$ & $-425,14$ & 472,50 & $-138,51$ & 158,52 & $-158,42$ & 204,16 & $-36,86$ & 38,59 & $-5,88$ & $-20,08$ \\
\hline$i=4$ & $-49,29$ & 130,00 & $-163,32$ & 72,31 & 14,27 & 4,24 & 102,35 & $-277,83$ & 221,96 & $-59,49$ \\
\hline$i=5$ & $-34,29$ & 148,61 & $-209,99$ & 108,46 & $-9,07$ & 5,28 & 148,05 & $-402,04$ & 326,24 & $-87,36$ \\
\hline$i=6$ & $-26,43$ & 171,39 & $-254,36$ & 139,21 & $-25,19$ & 5,84 & 195,20 & $-527,99$ & 430,83 & $-115,28$ \\
\hline$i=7$ & $-22,00$ & 181,11 & $-281,40$ & 159,72 & $-36,72$ & 6,88 & 226,86 & $-612,32$ & 500,77 & $-133,99$ \\
\hline
\end{tabular}




\begin{tabular}{|c|c|c|c|c|c|c|c|c|c|c|}
\hline$i=8$ & $-15,43$ & 176,11 & $-295,86$ & 173,15 & $-46,37$ & 8,00 & 237,74 & $-643,23$ & 527,13 & $-141,11$ \\
\hline$i=9$ & $-2,43$ & 157,78 & $-305,87$ & 186,94 & $-59,07$ & 9,20 & 233,48 & $-637,14$ & 523,93 & $-140,36$ \\
\hline$i=10$ & 25,29 & 113,61 & $-302,93$ & 206,37 & $-86,63$ & 10,80 & 230,68 & $-637,98$ & 529,72 & $-142,25$ \\
\hline
\end{tabular}

d) $\Delta D_{b}^{*}$ as a two-dimensional linear regression model:

$\Delta D_{b}^{*}=105,565 \cdot\left(d / D_{0}\right)+8,616 \cdot\left(H_{0} / D_{0}\right)-34,76$

The determinism coefficient of the model was $\mathrm{R}^{2}=0.987$, which indicates a fairly high agreement of the model with experimental data.

e) $\Delta H_{k}^{*}$ in the form of a two-dimensional linear regression model:

$\Delta H_{k}^{*}=84,995 \cdot\left(d / D_{0}\right)+2,736 \cdot\left(H_{0} / D_{0}\right)-20,6095$

The determinism coefficient of the model was $\mathrm{R}^{2}=0.996$, which indicates a fairly high agreement of the model with experimental data.

f) Determination of contraction angle $\varphi$ value:

$\varphi=138,92 \cdot\left(d / D_{0}\right)-1,228 \cdot\left(H_{0} / D_{0}\right)-32,075^{\circ}$

The coefficient of determinism was $\mathrm{R}^{2}=0.9904$, which indicates a fairly high agreement of the model with experimental data.

The obtained mathematical models make it possible to carry out an accurate calculation of the workpiece geometric parameters in terms of the final product dimensions, which makes it possible to take into account their shape change during the product assembly, which ensures that the exact configuration of the product is obtained at the output.

\section{Conclusions}

The calculation of a shaped blank is carried out during the manufacture of a composite tool for hole punching, which is a one-piece product made of X12M steels (rod) and U10A (shaped blank) with the following dimensions: $\mathrm{d}=12 \mathrm{~mm}$; $\mathrm{D}=31 \mathrm{~mm} ; \mathrm{H}=21 \mathrm{~mm}$. According to the results of the sample mechanical tests, the tensile strength of the permanent joint was 241-265 MPa per contact surface area unit of the product connected element.

They carried out the analysis of the geometric accuracy of the obtained one-piece product, after which the deviation value was obtained for the product mass equal to $7.57 \%$. Thus, a one-piece product was obtained with the deviation of geometric parameters within the range of precise hot forging, which is $5-25 \%$ by forging weight (volume).

\section{Summary}

The developed mathematical models of billet shaping make it possible to take into account the uneven deformation during assembly and guarantee the proper quality of the obtained one-piece product. That mentioned operation helps the examination of one-piece products obtaining by the deformation of plastic along with the needed bond strength and geometric accuracy.

\section{Acknowledgements}

The work is performed according to the Russian Government Program of Competitive Growth of Kazan Federal University.

\section{References}

[1] Ainbinder, S.B. (1957). Cold welding of metals, Univ. Latvian Academy of Sciences, Riga.

[2] Gmurman, V.E. (2003). Probability theory and mathematical statistics: Textbook for universities. - 9th ed. - M.: High school, - 479 p.: ill.

[3] Hartman, K., Letsky, E., Shefer, V. et al. (1977). Planning an experiment in the study of technological processes. Ed. by E.K. Letsky. Moscow: Mir, 552 p.

[4] Korol, V.K., \& Gildengorn, M.S. (1970). Fundamentals of production technology for multilayer metals. - M.: Metallurgy, $-237 \mathrm{p}$.

[5] Maslov, V.E., \& Shapoval, V.N. (1983). Experimental study of metal forming processes. - Kiev: High school. Head publishing house, $-232 \mathrm{p}$.

[6] Parks, I.M. (1953). Rekrystallzation Welding. The Welding Journal, 32(5).

[7] Romanovsky, V.P. (1979). Cold Forging Handbook. - 6th ed., rev. and add. - L.: Mechanical engineering. Leningr. department, - 520 p., Ill. 
[8] Shaparev, A.V., \& Savin, I.A. (2017). Calculation of Joint Plastic Deformation to Form Metal Compound in Cold Condition. Solid State Phenomena, 265, 313-318 DOI: 10.4028/www.scientific.net/SSP.265.313

[9] Valiev, A.M., Shibakov, V.G., \& Pankratov, D.L. (2016). Automated control system for the assembly of a composite punching tool. Russian Engineering Research, 36(2): 142-145. https://doi.org/10.3103/S1068798X16020234.

[10] Valiev, A.M., Shibakov, V.G., \& Pankratov, D.L. (2016). Design and manufacture of a composite punching tool. Russian Engineering Research, 36(2): 146-148. https://doi.org/10.3103/S1068798X16020246. 